\title{
THE POTENTIAL OF SOCIAL INDICATORS: MINIMUM CONDITIONS FOR IMPACT AT THE NATIONAL LEVEL AS SUGGESTED BY A STUDY OF THE USE OF 'SOCIAL INDICATORS' 73*
}

(Received 29 September, 1977)

\begin{abstract}
Empirical evidence is presented which suggests that the use of social indicators among upper level government officials in the United States is minimal at present. Further, the level of use is not likely to be increased by improved measurement procedures, aesthetically improved packaging, or more widespread dissemination of such information among persons who influence policy decisions. The power of such information can be expected to be no greater than that of 'mere' statistics unless deliberate effort is made to institutionalize the importance of social indicators into government operations in conjunction with policy planning, goal setting, and commitment to the use of indicators as a system of national evaluation of progress toward the achievement of societal objectives. Several recommendations are made to develop the potential of social indicators and to increase their creative and useful application in matters of public policy at the national level.
\end{abstract}

\section{BACKGROUN D}

Early in 1973 the Office of Management and Budget (OMB) released Social Indicators 1973 (SI '73).' The major objective of $S I$ '73 was to provide federal executives with an accessible compendium of policy-relevant social information in various categories including:

- Health: Longevity: the quality of health; freedom from disability; and access to health care.

- Public Safety: Safety of life and property from crime; fear of crime; and adequacy of the criminal justice system.

- Education: Level of basic education; opportunity for and participation in higher and continuing education.

- Employment: Opportunity for employment; attitudes concerning working conditions; and the quality and character of employment life.

- Income: Level of income; distribution of income; and expenditure of income.

- Housing: Housing quality; overall neighborhood satisfaction; comfort and living space.

- Leisure and Recreation: Time and facilities for leisure activities; patterns 
of participation and indication of recent change in those patterns; and locations of leisure activities.

The appearance of $S I ' 73$ marked the culmination of a long series of governmental efforts to organize and disseminate relevant social indicator data which began in $1933 .^{2}$ It has also been the most comprehensive and important of these efforts, with each chapter featuring an introductory text, technical notes, charts, and statistical tables of relevant indicator data derived from both federal and private research sources. To promote dissemination, OMB organized press conferences and distributed hundreds of free copies to potential users.

Shortly before the appearance of $S I$ '73, Nathan Caplan directed a study of the federal government's use of social science knowledge in policy-making (see Caplan et al., 1975). One major finding was that upper-level officiais in the executive branch shared a strong interest in social indicators and their relevance to the operations of their agencies. Ninety-four percent of the 204 policy-makers interviewed in the study reported that social indicator data would be valuable in formulating government policies and monitoring programs in their own agencies.

Many of the officials interviewed in Caplan's study became recipients of SI '73. This distribution outcome created an unusual opportunity to assess the volume's use and its impact on public policy decisions among a select group of national officials. Since the Caplan study had already generated considerable data on the use of social science knowledge among these persons in policy-influencing positions, ${ }^{3}$ it only remained to collect similar data on SI '73 from the same respondents after sufficient time had passed for the publication to become known. Its impact could then be gauged by comparing both sets of data.

Three factors strongly signaled the undertaking of this assessment: (1) The high level of interest expressed by Caplan's respondents in social indicators; (2) the apparent correspondence between what those officials said they wanted and the information contained in $S I$ ' 73 ; and (3) the broad dissemination and accesibility of the report. In short, the fortuitous publication of this document in 1973 presented a unique opportunity to test the usefulness of the kind of information many social scientists see as the best resource for policy decisions leading to societal improvement. 


\section{PURPOSE AND OBJECTIVES}

The main purpose of the research was to assess the use of $S I$ ' 73 in policyrelated decisions among upper level federal executives. More broadly, we also expected to gain a perspective on the general use of social indicator data, by comparing the use of $S I$ '73 with data collected earlier from the same respondents.

\section{METHOD AND DESIGN}

\section{Overview}

The primary feature of the research design was to reinterview the 204 respondents included in the original Caplan study. We questioned these respondents about their use and knowledge of social indicator data in general, and $S I$ ' 73 in particular.

\section{Respondents}

Approximately one year after the appearance of SI '73 (and the conclusion of the interview phase of the Caplan study), we made telephone contact with the original 204 respondents to determine whether they had remained in the same job. If not, we noted their new positions and addresses, as well as the names of their replacements. Of the original 204 respondents, 136 had remained in their jobs, and we located 66 of the 68 who had changed positions. Thus, it was possible to reinterview 202 of the original 204 respondents. We decided that the 68 replacements should also be interviewed so we could analyze data by role position even if job changes had occurred. Thus, the study included a total of 270 respondents -202 original respondents and 68 replacements.

\section{Interview and Procedures}

We gathered two types of interview data: (1) mail questionnaires and, (2) personal, in-depth interviews.

Mail questionnaire. Mail questionnaires were set to the 270 respondents in order to gain broad survey-type knowledge of their use of social indicator data. The questionnaire was designed primarily to guage the extent of their 
awareness and utilization of $S I$ '73. Questions covered areas such as: How many respondents were aware of and had used $S I 73$; how had they become aware of $S I$ '73; what was their estimate of the potential utility of $S I$ ' 73 , in specific public policy areas; and whether awareness, or utilization of $S I$ ' 73 , had stimulated other agency activities, such as research.

The mail questionnaire was also designed to determine if the respondents' use of SI ' 73 was linked to their knowledge and use of social indicators from other sources. Thus the questionnaire included items to explore respondents' awareness and use of social indicator data generally. These items were designed to parallel those constructed to elicit information about $S I$ ' 73 .

By comparing data on the use of $S I$ ' 73 with data on the use of other kinds of social science information (such as that gathered earlier from the respondents in the Caplan study, and from other sources), we expected that certain hypotheses about the nature of the utilization process and factors affecting it could be tested. In turn, these data could be used as a basis for recommendations to improve the usefulness of the publication and how it could be promoted more successfully.

Personal interviews. Personal in-depth interviews were designed as a supplementary follow-up to the mail questionnaire when we determined an inadequate and low response rate. The nature of these interviews and the type of respondents involved are described later. We conducted 28 such interviews, 12 by phone and 16 face-to-face. All of those interviewed were among the 270 who also had received the mail questionnaire.

\section{Procedure}

In July 1975, approximately one year and five months after the appearance of $S I$ '73, the mail questionnaire was sent to each of the 270 respondents accompanied by a covering letter. The letter thanked the respondents for their previous cooperation and requested their completion of the enclosed questionnaire as a necessary supplement to the previously collected data. The respondents were further informed as follows:

Having now gathered and analyzed these data, it is apparent that there are a number of areas in which it would be important to have additional information. This is particularly true with respect to the use or nonuse of social indicator information. Accordingly, we are requesting that you fill out and return the enclosed questionnaire within the next few days, if possible. Your cooperation will be greatly appreciated. 
A modified version of the covering letter was also sent to new personnel in the previously interviewed positions.

\section{Response Rate}

Based on Caplan's earlier success in interviewing respondents, it was expected that the response rate for the mail questionnaire would be satisfactory for refined statistical analysis. In the Caplan study, 95 percent of those officials who received a letter outlining the purpose of the research either agreed to be interviewed face-to-face, or suggested a colleague as a suitable substitute. Such a response rate is high for survey research. Given the level of responsibility of these respondents and their job pressures, this high rate is all the more significant. Furthermore, almost all respondents permitted their interviews to be taped. Some made special arrangements for the interviewers to gain access to their buildings conveniently, and some set aside the better part of the moming or afternoon for the interviews, even though no more than one and a half hours had been requested. Interviewers repeatedly described the respondents as 'gracious', and attributed their cooperation to interest in the purpose of the project as outlined in the letter (i.e., the determination of how social science information is utilized by government agencies, and what may be done to facilitate its use).

Responses to a number of interview items in the prior study also indicated a high level of receptivity and interest in the area of utilization: Over 85 percent subscribed to the belief that social sciences knowledge can contribute to the improvement of government policies; 90 percent said they believed government should make the fullest possible use of social science information; and, of special importance with respect to the questionnaire, 94 percent responded affirmatively when asked if a set of measures indicative of the quality of life in the nation could be of value to the operation of their own department or agency.

Despite these reasons to expect a high response rate to the $S I$ '73 questionnaire, the percentage of returns was no more than average for selfadministered mail questionnaires. Even after follow-up letters and phone calls to urge cooperation, only 115 of 270 (43\%) questionnaires were completed and returned within four months of their mailing.

Efforts to account for this lower-thanexpected response rate on the basis of some possible respondent or instrument bias proved fruitless. For example, 
a number of statistical comparisons made between respondent and nonrespondent groups using data collected in the Caplan study (such as a history of low or high level use of social science data) did not reveal differentiating features. Items such as the levels of utilization of social science information and attitudinal differences with respect to utilization turned out virtually the same for those who returned the questionnaire and those who did not.

Even though lower than anticipated, the 43 percent response rate would not have been terribly important if a sizable proportion of those responding had been familiar with or had used $S I$ '73. But, as will be shown shortly, too few respondents either used or were sufficiently familiar with the volume to permit statistical treatment of the data - at least, not the sort of analysis originally planned. Further, it soon became evident from personal interviews with those who did not return the questionnaire that no fine-grain quantitative analysis could have been conducted even if all questionnaires had been returned: Too few respondents were sufficiently familiar with the publication to provide the necessary data.

Therefore, in October of 1975 efforts to increase the return rate for the mail questionnaire were abandoned, and research energies were concentrated on in-depth personal interviews designed to gain an understanding of why use and awareness of $S I$ ' 73 were so limited.

\section{RESULTS}

\section{The Use of $S I{ }^{\prime} 73$}

Of the 115 respondents who returned the questionnaire, four percent (5) reported that they had actually used $S I$ ' 73 .

The determination of use was based on the responses to six separate items in the questionnaire. These items were arranged and worded to funnel down from the general to the specific, thereby allowing respondents' comments on $S I$ '73 to emerge spontaneously before probing more directly. The sequence of relevant items arranged in the order of their appearance in the questionnaire appears below. In addition, a 'yes' response to each of these items led off to a sub-series of related items. In those related questions, the respondent was requested to (a) provide a description of the policy issues involved in the utilization instance, and (b) identify the specific social indicator data used and their source(s). 


\section{Selected Questionnaire Items Measuring Utilization}

- Have you ever referred to social indicator data in making a policyrelated decision?

- Has any indicator data been provocative enough in its own right to influence you into considering a new policy or re-evaluating an existing one?

- Have you ever used social indicator data to support a policy decision after it has already been?

- If not indicated earlier, have you ever consulted Social Indicators 1973 in making a policy-related decision?

- Has awareness or utilization of Social Indicators 1973, or social indicator activity in general, stimulated any research in your agency?

- On the basis of your experience in the Federal Government, can you think of instances when a new program, a major program alteration, a new social or administrative policy, legislative proposal, or a technical innovation could be traced to Social Indicators 1973 ?

Saliency and impact. While over a third of those who returned the questionnaire (42 respondents out of the total of 115 returns) said they had used social indicator data in response to the first three items listed above, only a few spontaneously mentioned $S I$ ' 73 . The rest mentioned it only when directly questioned in the fourth item, i.e., "... have you ever consulted Social Indicators 1973?"

The data on the purpose for which our respondents turned to $S I$ ' 73 information were no more encouraging than those on the level of selfreported use. In the mail questionnaire they reported using it predominantly as background reference, such as to help prepare speeches.

\section{Awareness and Distribution of SI '73}

To measure awareness and distribution, we asked another set of 'funneldown' type questions similar to those for utilization. The items are listed below in the order of their appearance in the questionnaire. A 'yes' response to any of these branched off into a series of related sub-items. 
Selected Questionnaire Items Measuring Awareness and Distribution

- Are you familiar with social indicator data?

- Have you for any reason purposely disregarded or rejected relevant social indicator data in making a policy-related decisions?

- Are you aware of the existence of Social Indicators 1973 (SI '73)?

- Do you own a copy of $S I$ '73?

- Have you ever for any reason purposely disregarded or rejected $S I ' 73$ data?

- Does anything about $S I$ '73 stand out for you?

Twenty-two percent (25) of the respondents who returned the questionnaire $(N=115)$ reported some degree of awareness of the existence of $S I$ '73. This included 16 percent (18) who reported familiarity with its contents and six percent (7) who reported knowing about $S I$ '73 but who, at most, had merely leafed through it without reading. Seventy-eight percent (90) of the respondents who returned the questionnaire reported that they were totally unaware of the publication.

One of the objectives of the survey was to trace the basis for awareness of $S I$ '73. The data on distribution are based on a set of spinoff items that followed 'yes' answers to 'Are you aware of the existence of Social Indicators 1973 ?' The particular items are shown below to illustrate how questionnaire items were supplemented by sets of sub-items, as well as to show the source of the data to come. 
8. Are you aware of the existence of 'Social Indicators '73'(SI '73)?

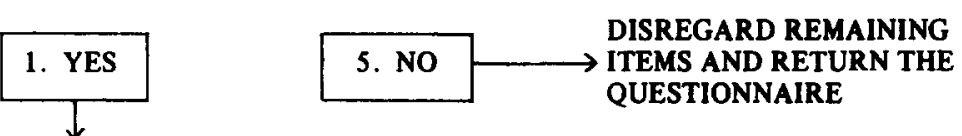

If so, please indicate if you:

8a. Have read a copy of SI '73?

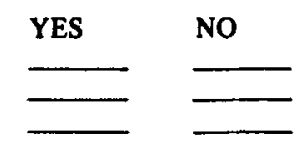

8b. Have seen, but not read, a copy of SI '73'?

8c. Have read about SI '73?
1. YES

5. NO

$\rightarrow$ GO TO QUESTION 9

If so, please indicate where: (check where response is yes)

Staff

Inter-agency communication

Newspaper(s)

If possible, please specify

Magazine(s)

If possible, please specify

Other. Please specify

Of the 26 respondents who knew of $S I$ '73, 23 percent (6) had learned about it through routine staff communication channels, fifteen percent (4) through inter-agency communications, and thirty-eight percent (10) had read about it in newspapers, press releases, or magazines.

Half (13 out of 26) of those reporting awareness of $S I$ ' 73 either owned a copy or had ready access to one; ten of these copies came from either OMB, or through agency purchase. Three respondents (nonusers) had purchased their own copies. As far as passing $S I$ ' 73 on to others, four reported that they routed it onto subordinates, and two sent copies to their superiors.

\section{Potential Utility}

We asked mail respondents familiar with $S I$ ' 73 to rank its possible utility. The questionnaire item used to measure this variable appears below. We included the same item in the personal interview to question respondents who had not returned the questionnaire, but knew about $S I$ ' 73 . 
Please rate the utility of $S I$ ' 73 in the following areas from 1 to 5 , with ' 1 ' meaning that it is 'Not too useful', and ' 5 ' meaning 'Very useful'. (See Scale Below)

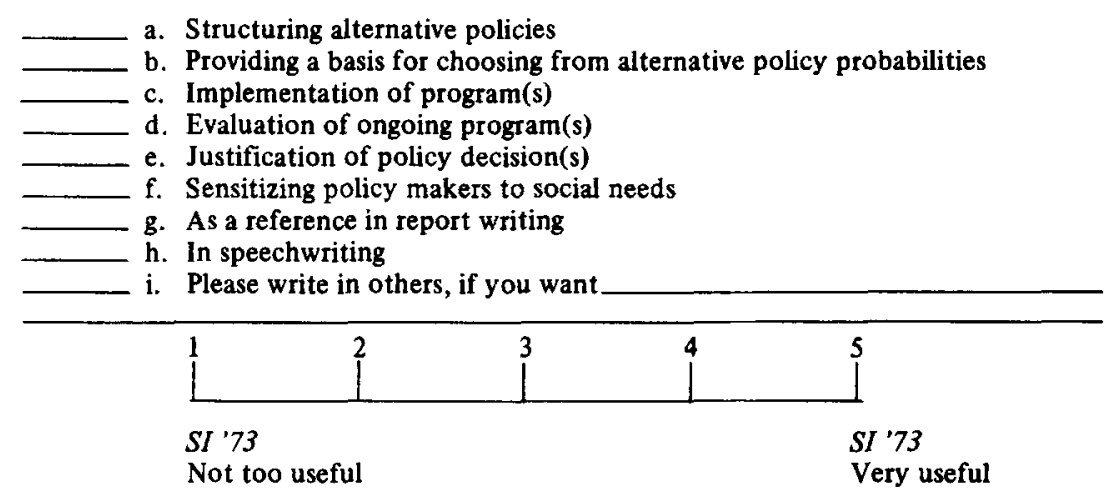

No clear consensus emerged in terms of ranking SI '73 on usefulness. Respondents, however, did agree on the decision areas where they considered the publication least helpful, namely 'implementation of programs', 'structuring alternative policies', and 'providing a basis for choosing from alternative policy probabilities'. They did find $S I$ ' 73 'somewhat' potentially useful in 'speechwriting', as a 'reference in report writing', and as 'justification of policy decision(s)', and only in these categories did any respondents $(N=3)$ rank $S I$ ' 73 'very useful'. They viewed its potential for 'sensitizing policy makers to social needs' as moderately important.

\section{Relationship of Use and Awareness of SI '73 to Use and Awareness of Other Sources of Social Science Data}

Since an objective of the questionnaire was to determine if the respondents' use of $S I$ ' 73 was dependent on their awareness and use of other social science information, comparison of utilization scores were made with those derived from the prior Caplan et al.study (cf.pp. 14-16). A slight difference emerged. Thirty-two percent of the high users from the Caplan study and 39 percent of the low users cited additional instances of use involving social indicatortype data. That is, self-reported use of social indicator data is the SI '73 study was found to be slightly more common among those respondents who had been classified as the less frequent users of social science information based on the prior study. 
While the significance of this finding is not fully clear, these data do show that the use of social indicator data does not depend on the use of other forms of social science research data. By contrast, however, awareness and use of $S I$ '73 appeared to be closely related to the use of other social science knowledge. Only one-fifth of the low utilizers were aware of $S I$ ' 73 in contrast to almost one-half of the high utilizers. Thus, only the most frequent users of social science research were likely to be aware of $S I$ ' 73 . The close dependency between awareness of $S I ' 73$ and the use of other social science data is made even more striking by the fact that every respondent familiar with $S I$ ' 73 was also a user of social indicator data from other sources.

From these findings, it is possible to conclude that (1) those with a history of frequent use of social science information apparently made the effort to examine and assess the $S I$ ' 73 material, thus their reliance on other sources of information was not due to ignorance of $S I$ '73, and (2) there is no evidence that $S I ' 73$ created new users among persons without previous experience in the use of social science data.

\section{The Use of Social Indicator Data in General}

Slightly more than one-third ( 37 percent) of the respondents who returned the mail questionnaire reported that they had used social indicators. Most of these respondents reported using such data on an on-going basis. The indicator data sources they mentioned most frequently included publications by the Census Bureau, HUD, Department of Labor, and HEW.

The instances of use cited by users of social indicators from the earlier Caplan study were strikingly different from those mentioned by users of SI ' 73 in the present study. The SI ' 73 users gave vague and impressionistic accounts of their utilization. By contrast, the self-reported users of social indicator data from other sources provided detailed descriptions of what information they used, the particular policy issue involved and some estimate of the impact of the information on the outcome of their policy deliberations. For instance, these respondents mentioned using specific indicators in policy areas such as: the cost/benefits of measures to improve highway vehicle safety, youth programs, career education, programs for the medically needy, the level and mix of manpower programs recommended to the President, and so on.

Another difference between $S I ' 73$ and other social indicators in our 
sample concerned the degree of impact. Unlike all of the $S I$ ' 73 users who answered negatively, almost all users of other social indicator data in our sample answered the following question affirmatively: "Has any indicator data been provocative enough in its own right to influence you into considering a new policy or re-evaluating an existing one?" Such instances of utilization included policies in health, unemployment, traffic safety, recreation, and other major areas. There is reason to believe, however, that what many respondents reported as use of social indicators was no different than the use of routine statistics for routine policy-related decisions. Some respondents did cite instances where statistical material was merged in order to create an index, such as the state of a particular policy concern over time, such as higher education. It is evident, however, that the respondents show a distinct preference to premise such decisions on information from sources other than $S I$ '73, even though the data may be somewhat similar.

When we originally began this study, we anticipated that $S I$ ' 73 would be generally known to policy makers - an assumption we soon found to be incorrect. Thus, much of our research effort had to be devoted to discovering what went wrong and why. This meant abandoning an ambitious research design and adopting a strategy more akin to detective work than to routine social science research. Consequently, the amount of data and level of analysis in this report is more qualitative than we would have preferred, and the conclusions more tentative. However, we hoped that what we might have lost in quantitative rigor, we gained in qualitative understanding.

\section{SUPPLEMENTARY: PERSONAL INTERVIEWS}

By any standard, the level of $S I$ ' 73 use our respondents reported must be considered low - seriously low in view of the interest in social indicator data they expressed in the Caplan study. From the standpoint of OMB and all those associated with the social indicator movement, this level of use is quite simply disappointing. Consequently, we designed the personal interviews to probe for information that might account for $S I$ '73's failure and might shed some light on its implications.

The low level of use and awareness of $S I$ '73 raised a number of questions, the first of which pertained to the accuracy of the finding itself. Was the level of self-reported use actually that low, or did it result from factors 
associated with the use of the self-administered mail questionnaire? One of the first objectives of the interviews was to estimate the accuracy of our questionnaire data.

Respondents. The 28 personal interviews were conducted with the following respondents: four self-reported users of $S I$ '73; 12 who reported familiarity with $S I$ ' 73 , but nonuse of its information; and 12 persons classified as high users of social science data in the Caplan study, but who failed to return the mail questionnaire. Our presumption was that by conducting follow-up interviews with these particular respondents we would be most likely to tap those persons who could provide us with pertinent information on matters such as: the use (or nonuse) of $S I$ '73; the unexpectedly low response rate; and information associated with social indicator use in general.

Results. The results of these personal interviews corroborated the results of the mail questionnaire: $S I$ ' 73 was rarely used among persons in policy. influencing positions, and when it was used it was generally for background information, not always in policy-related situations.

We first contacted four of the five respondents who reported using $S I$ ' 73 . The picture they painted for us differed little from what we learned from their mail questionnaires. If anything, these follow-up interviews were even more discouraging. Of the four self-reported users, one respondents did not recall reporting that he had used $S I$ ' 73 , and two others who had reported using $S I$ ' 73 data explained that they or their agency had supplied the data to OMB for inclusion in the volume subsequent to the utilization instance cited in the mail questionnaire.

Of the 12 'high user' interviewees who had not returned the questionnaire, three had neither seen or heard about $S I$ ' 73 , and five had heard about, but not seen, the volume. Of the four who had seen it, three were familiar with its contents.

Respondents who reported unfamiliarity with $S I$ ' 73 . during their interviews received free copies and were later reinterviewed for their reactions. In general their opinions matched those of respondents who had initially reported familiarity but who had not used the volume. They found the inforformation in $S I ' 73$ to be of little value in their work. While use certainly requires initial familiarity, these interviews suggest (as do other data sources, e.g., nonusers from the Caplan study who bought their own copies of SI '73) that increased exposure, through wider distribution, would not have produced an appreciable effect on the level of utilization. 
In general, the descriptions of the application of $S I$ ' 73 data by the nonreturn respondents did not differ substantively from the instances of use cited by the five respondents who returned the questionnaire. SI '73 data had found use only as a source of general or background information, such as in speechwriting or report writing, not in policy related deliberations or matters of similar importance. Although the utilization level of these 12 respondents was indeed higher than for those who returned the mail questionnaire, it does not indicate that the low level of use associated with the mail questionnaire was the result of instrument problems or self-selectivity bias among respondents. In all probability, the level of utilization for these twelve respondents is artificially inflated: the very reason they were chosen was because of their past history of frequent social science utilization. Further, the instances of use cited by these respondents were nebulous and could no more qualify as evidence of policy-related use than those provided by the five respondents who returned the questionnaire and reported use of $S I$ ' 73 .

\section{Positive Features}

Not all of the comments on $S I ' 73$ were negative, and in order to gain a balanced presentation of the respondents' evaluative remarks, we present their positive views as follows:

1. Format. When asked what stood out about $S I$ ' 73 , half the respondents mentioned graphics and layouts. Even the most severe critics commented favorably on its beautiful colors and graphic displays' (e.g., "SI '73 is striking in its format and is very well done, conscientiously put together to give the basic essence of the data, but it falls down as far as usefulness".).

2. Areas of interest. Respondents generally were in agreement that the topics selected were appropriately balanced in emphasis. It should be noted, however, that while respondents were favorable to the parameters of life experience represented, they did not comment on the appropriateness of the indicators to the areas of policy concerns. For example, they mentioned the appropriateness of 'Health' as an area of importance, but did not pass judgment on the appropriateness and adequacy of 'Long Life', 'Disability', and 'Access to Medical Care' as health indicators. The immediate relationship of these 'statistics' to national goals appears not to have been analyzed in any penetrating manner by the respondents. ${ }^{4}$

3. Compendium. The respondents liked the organization of the publica- 
tion and were particularly favorable to the parsimonious encompassing of statistics from a variety of policy areas into one volume. The following was a typical comment: "While the Bureau of the Census and other government agencies produce very similar statistics, the fact that $S I$ ' 73 was a compendium definitely was an advantage". Within these policy areas, however, $S I$ ' 73 was nòt viewed as presenting a new configuration of data which would distinguish it qualitatively from other statistical data.

4. $O M B$. The fact that $S I ' 73$ was produced by OMB may have determined its level of use was carefully considered in the interviews. Our general impression was that the majority of respondents were neutral toward OMB's involvement in $S I$ ' 73. A small minority felt some bias against OMB because of its possible 'watchdog' role and preferred data from a 'neutral' agency, such as the Bureau of the Census. On the other hand, several respondents, perhaps those more sensitive to the possible relation of indicators to national gcals, argued that it would be advisable to have OMB continue activities in the social indicator area because it, more than any other government agency, "carried more weight and lent credibility to budgetary requests relating to the achievement of social objectives in the areas covered in SI '73".

5. Objectivity. It has often been stressed that objectivity is of major importance in influencing utilization. Accordingly, we asked whether respondents had purposely disregarded or rejected policy relevant $S I$ ' 73 data because it lacked objectivity. No respondent reported that she/he rejected SI '73 data on grounds of objectivity. In general, they were familiar with the data sources and felt they could be trusted to provide objective data. ${ }^{5}$

\section{Reasons for Nonuse}

1. Reliance on other sources of data. The most frequent reason given for nonuse of SI '73 centered on the nonusers' feeling that other sources of similar information were more relevant and easily accessible.

Many respondents felt that $S I$ ' 73 was a rehash of other easily available data, particularly the Bureau of Census publications. One-third of those interviewed personally mentioned that they considered $S I$ ' 73 redundant because of the Bureau of Census' Statistical Abstracts and Continuing Population Survey, which they considered to be more useful.

A more typical response came from one person in the Department of the Interior who said that he "... didn't dig into it that much. When it came, I 
looked at $S I$ '73 but decided that it contained most of the same statistics as the Bureau of Census". Another respondent felt that while the format of SI '73 was 'gorgeous', it wasn't as useful as HEW's statistics. More often, however, respondents said they preferred to use 'indicators' from their own agency.

2. Issues of scope. Several respondents thought that the overview presented by $S I$ ' 73 was one of its strong points. The majority, however, felt that it was too general in scope to be useful, and would have preferred data which could be disaggregated to geographic levels. They frequently cited very specific indicator needs which either were being met by their own agency's research staff or other sources. For instance, a respondent in the Department of Labor said that his agency relied heavily on data at a local level and that the data in SI '73 could not be disaggregated to suit his needs. He felt that aggregate indices at the national level were only marginally useful. A respondent from NIE reported that his informational needs were sometimes very specific, such as "how many unmarried mothers of three of more children live in Appalachia", and that a volume such as $S I$ ' 73 could not meet such needs. Another respondent referred to $S I$ '73 as a useless collection of "wall-to-wall macrodata".

3. Lack of interpretation and integration. Respondents were asked about their attitudes toward the provision of interpretation of the data in $S I$ ' 73 . Practically all respondents stated that the $S I$ ' 73 information was stark (e.g., "its significance did not 'spring to life', as it reflected a body-count mentality"), and that the report needed commentary and interpretation to increase its usefulness; otherwise, it merely told them what they already knew or could easily learn from other sources. The attitude toward the inclusion of an interpretation of the data seemed to be "the more the better", with the majority in favor of a "... broad and more meaningful view" brought together in an integrated fashion. One respondent reported that the volume provided no sense of social reality and that a book of essays based on the data would have been preferable.

This desire for interpretation, however, was not made without some reservations. While most of the respondents favored 'interpretation', we heard considerable disagreement over who should do it. In fact, once the issue was raised, some respondents began to reconsider its advisability. The problem centered on OMB. As mentioned earlier, most respondents had no objections to OMB organizing and publishing such social indicator reports 
periodically, but these same persons had serious reservations regarding the advisability of that agency providing interpretation. Practically all respondents who favored interpretation did not want it to be provided by OMB. The most frequently cited objection to OMB providing interpretation was fear that $\mathrm{OMB}$, as a 'watchdog' and politically partisan agency, was capable of interpreting the data to suit their bureaucratic and political convenience.

The general opinion was that OMB should not provide interpretation for any data other than that which it collected directly. A specific alternative suggested by respondents was that the responsibility for data analysis, text expositions, and interpretation be given to a 'neutral' group or agency. The most frequently suggested were HEW, Bureau of the Census, or a nongovernment agency. Another alternative was that the interpretation for each policy area be provided by the agency furnishing the data.

4. Obsolete data. A number of respondents commented that they require more data on current conditions, rather than 'better' data on past conditions. Recognizing that such a volume would necessarily have to rely heavily on information collected earlier by other governmental agencies, these same respondents expressed pessimism over the possible utility of such publications for future planning.

5. Absence of trend data and trend interpretation. The criticism of $S I$ ' 73 on failure to organize and show trends over time came as somewhat of a surprise. Even after casually leafing through the publication, one is impressed with the number of charts and tables showing data organized to illustrate time trends. Yet several respondents mentioned the absence of trend data as a major shortcoming. We reinterviewed a number of respondents specifically to gain clarification of this criticism. It appears that four issues are involved.

(a) SI '73 contains many charts of time series data with different colored trend lines. These were viewed as outstanding examples of the way such data should be presented. Some respondents felt, however, that the many tables containing time series data (i.e., where the raw data are presented by year), were boring and overwhelmed their capacity and patience to assimilate the data and search for trends, especially persons who did not routinely deal with raw data. Thus, they felt that whenever possible, time trend data should be summarized and presented in charts with multicolored trend lines.

(b) Many respondents felt that the meaning and significance of the trend data, even when presented in chart form, were not satisfactorily discussed in the text. While the technical information explaining data-gathering and 
procedures for normalizing the measures (to adjust for year-to-year differences in data gathering procedures) were abundantly available and clear, they criticized the lack of a substantive interpretation of these charts specifically in terms of their policy relevance.

(c) In addition to the need to call attention to certain trends, they also felt that too much of the time series was devoted to narrowly defined issues (e.g., number of persons working part time), and too little attention given to data on "... broader trends in community life". Specific recommendations pertained to including objective and attitudinal data on family and neighborhood life, trust in government, and the like.

(d) Finally, some of the respondents commented on the lack of before and after time series data that would permit the possibility of gauging the effect of government programs on societal conditions.

6. Insufficiency of 'quality of life' and 'subjective' indicator data. We also questioned respondents on their attitudes toward 'quality of life' indicators, and whether they perceived the data in $S I$ ' 73 as falling into that category. Most of the respondents felt that $S I$ ' 73 did not contain quality of life data. Many respondents specifically mentioned being disappointed by the overreliance on 'easy-to-measure' quantitative data in $S I$ '73, and said they would have preferred more subjective data on personal and value-oriented concerns. They expressed considerable interest in the need to go beyond objective indicators and provide subjective measures of life experience and social wellbeing. Some went so far as to suggest that a separate volume on quality of life data would be helpful. In the words of one respondent: "Because of the complexity of life, some measure of satisfaction or purpose might be valid and it would probably be a better indicator of quality of life than straight health, crime, education, etc., statistics".

\section{Summary of Major Findings}

1. Upper level governmental officials rarely used $S I$ '73. No more than four percent of our sample made use of it in connection with their work. Furthermore, only 22 percent of the sample expressed any degree of awareness of $S I$ '73. By contrast, the use of social indicator data from other sources was comparatively high, with over one-third of the respondents reporting instances of policy-related applications of such information. 
2. The few uses made of $S I$ ' 73 mainly involved the application of information in supplementary roles, such as for speechwriting and background reference purposes. No one reported that $S I$ ' 73 data played an important role in any policy-related decision. On the other hand, respondents cited numerous instances in which social indicator data from other sources had an impact on important matters of policy.

3. A majority of the respondents returning the questionnaire reported that they were totally unaware of $S I$ ' 73 . About 25 percent of the respondents had at least heard of the publication, but only about one in five showed any real degree of familiarity with it. Four (nonusers) owned desk copies. The rest said copies undoubtedly could be found some where in their agency. Those who knew about $S I ' 73$ were also the most likely to have had a past history of being frequent utilizers of social science information in general. By contrast, the use of social indicator data from other sources appeared to be more persuasive and to occur independently of the respondents' past experience with social science data use.

4. Of those who reported awareness of SI '73, the largest percent (over one-third) learned about it through the news media.

5. The officials cited a variety of factors as responsible for the low level of $S I 73$ use. Most prominent among these were: routine availability of identical or better data from other sources; narrowness of $S I$ '73's scope of information; obsolescence of $S I$ ' 73 data; lack of interpretation, especially with respect to time series data, and insufficiency of data on subjective matters involving attitudes, values, and personal aspects of social well-being.

On the positive side, the graphics and the idea of a compendium were particularly well liked. This response suggests that while effective packaging and dissemination of information may increase awareness, they do not guarantee utilization. In fact, their effect on utilitzation appears to be negligible. The negative appraisals of respondents reporting unfamiliarity with $S I$ '73 during the personal interview who were then sent copies for review suggest that increased exposure, through dissemination, would not have produced an appreciable increase of utilization.

6. The differences in frequency of use, impact, and potential usefulness between $S I$ '73 information and social indicator data from other sources suggests that the discouraging results do not reflect a more general orientation to social indicators. Social indicator development continues to hold potential as a promising line of endeavor. The apparent failure of $S I$ ' 73 to impact upon 
the policy-maker community appears to be due to factors specific to that publication.

\section{DISCUSSIONS AND CONCLUSIONS}

We found two main reasons for the failure of $S I$ ' 73 . The first pertains to the organizational and bureaucratic factors impinging on the utilization process itself. The second pertains to factors specifically associated with the perceived lack of power of information of $S I$ '73 in comparison to other social indicators. It should be emphasized that our discussion of this volume's failure raises issues applicable to other social indicator endeavors and is not meant to single out $S I$ '73 for special condemnation. We will also touch on factors related to the objectives of $S I$ ' 73 in relation to the larger context of national policy considerations.

\section{Bureaucratization of Information}

Knowledge utilization of any kind does not occur in a vacuum. The utilization of scientific information in the formulation of public policy, even under ideal conditions, results from a complex and often seemingly capricious set of circumstances, many of which are related to bureaucratic and organizational variables. Utilization is a deliberate process often designed to serve ends which are more bureaucratic than objectively informational (Caplan, 1976a; Caplan and Rich, 1976; Barton and Rich, 1976). As the findings suggest, the principal purpose served by knowledge utilization may not be to provide objective fact gathering and analysis, but to reinforce the information policy of the using agency and to maintain and strengthen the pre-existent bureaucratic arrangements associated with the acquisition and processing of information in accord with that policy. Thus, the organization's information policy can take precedence over the substantive content or significance of the information.

Caplan and Rich's findings illustrate how the acquisition, processing, utilization, and application of information become ensnarled in a Laocoön of bureaucratic actions which intensify rather than reduce resistance to the utilization of scientific knowledge in decision making among upper-level Federal executives. Rich and Barton (1976) found that even agencies which are mandated to fund research applicable to meeting national needs and goals 
often did not utilize information from projects they sponsor when it came to determining the design and choice of new projects for sponsorship.

The current study did not focus on identifying the organizational and bureaucratic factors which affected the use of $S I$ '73. Rather, the scope was limited to problems related to $S I$ ' 73 itself. While organizational and other variables may set the context for the use of data, such as $S I$ '73, the control of these forces lies largely outside of the power of most data-producing agencies. Hence, further discussion and recommendations will center on the cluster of factors related to the power of information and the potential usefulness of $S I$ ' 73 at the upper levels of governmental power and responsibility.

\section{SI '73 and the Power of Information}

Social indicators have a variety of meanings. But, regardless of whose definition is used, there is sufficient agreement in the literature on the more important attributes that such data should possess:

- A social indicator ought to be a noneconomic measure of a social condition important to the social state of a nation.

- The measure should be quantifiable, sensitive to change, and presented as time series data so that changes in social conditions can be monitored overtime.

- Such data should contain prior, during, and after measure so as to allow for the assessment of meliorative government programs designed to improve social conditions.

- Social indicators should also be anticipatory and suitable for social forecasting in order to facilitate long range social planning.

- Upper-level federal officials should have: [1] a serious commitment to the future improvement (i.e., national goals) in the social conditions measured by the indicators; as well as [2] a commitment to the use of indicators as the legitimate yardsticks of progress in achieving those goals.

- And finally, a social indicator should be part of a system of indicators organized around an analytical model or theoretical perspective designed to account for observed changes. As indicators accumulate, this would make it possible to say not only something about the state of the social system, but also something about the nature of the system, how it functions, and to improve it. ${ }^{6}$ 
From these definitions, the impression emerges that social indicators may best be thought of as lying somewhere between social statistics and social goals. With regard to social goals, indicators represent important social objectives to the extent that the latter can be made amenable to direct measurement. With regard to social statistics, indicators represent more than 'raw facts' or empirical referents since they also have some of the qualitative characteristics of a goal in that they measure concepts and objectives. Thus, social indicators are more than a measurement, but less than a goal; or, perhaps better still, they are some of each.

It is impossible to say at what point a social indicator becomes different from a social statistic, but it seems clear that on the whole, the statistical data in $S I$ ' 73 lacked the minimal prerequisites of advancement to the role of social indicators. The $S I$ ' 73 data carried no implication of a shared set of goals or commitment to improving salient social conditions; nor did it carry a commitment to use the specified indicators to monitor change resulting from governmental programs as a basis for judging to what degree conditions have improved, or gotten worse. Cogency, utility, pertinence, and applicability - features generally considered as increasing the power of information were not viewed as attributes of the $S I$ ' 73 information. Consequently, the data carried no more weight than 'mere' statistics, most of which were already known or easily available from other sources. ${ }^{\text {? }}$

It would be expected then that those charged with the responsibility of gathering and presenting social indicator data would design indicators that represented broad gauge measures of important aspects of social life. These aggregate goal-related measures would enable governmental officials to use indicators as yardsticks in evaluating social progress and the impact of ameliorative steps on the public. The authors of $S I{ }^{\prime} 73$ acknowledged the functions of social indicators, as well as the power of information that distinguish social indicators from other forms of data, in the Introductory remarks to $S I$ ' 73 as follows:

The concerns have been defined and selected to reveal the general status of the entire population; to depict conditions that are, or are likely to be, dealt with by national policies; and to encompass many of the important issues facing the Nation.

The concerns thus embody widely held basic social objectives: Good health and long life, freedom from crime and the fear of crime, sufficient education to take part in society and make the most of one's abilities, the opportunity to work at a job that is satisfying and rewarding, income sufficient to cover the necessities of life with opportunities for improving one's income, housing that is comfortable within a congenial environment, and time and opportunity for discretionary activities. 
For each of the identified social concerns, one or more indicators - statistical measures of important aspects of the concerns - have been identified.

Ideally, an indicator would show, in a timely fashion, the status of the population in relation to a particular concern. It could be disaggregated to show which groups of the population were affected, and it could be linked statistically with other indicators to relate change in one condition to change in another. Thus, an indicator would reveal not only the status of the population in relation to a perceived social objective, but it would also furnish some idea of what forces were influencing that status. At the present time, not enough is known about the cause and effect of social conditions to develop such ideal indicators. Rather, the indicators presented in this publication represent simply a first step toward the development of a more extensive social indicator system. (Social Indicators, 1973, p. xiii)

While those responsible for $S I$ ' 73 may have recognized the need for such a conceptual basis, they did not integrate the material to encompass such an orientation. Consequently, potential users of indicator data did not view the material contained in $S I ' 73$ as high powered information. In fact, they viewed it as having no greater utility than a collection of social statistics. Moreover, their perception is understandable. Other than for these few remarks in the Introduction to $S I$ ' 73 , the volume hardly alludes again to the conceptual significance of indicators vis-à-vis social statistics. Instead, these brief introductory comments are followed by 258 pages of tables and charts of data with minimal commentary and interpretation of any type. For all practical purposes these introductory remarks remain isolated from the body of the report, and reveal a gap between what was promised and what was. provided. 8

Increasing the power of information. The overwhelming impression from the reactions of policy makers in the survey was that they did not regard information contained in SI '73 of sufficient power to be of use. This consensus raises the critical question of how the power of information in $S I$ '73, and other form of social indicator-like information, could be increased. Of course, increasing the potency of data is no guarantee that they will be used as various organizational and other factors mentioned earlier also influence utilization. Nevertheless, improving data to correspond more closely to the objective needs of policy makers increases the probability of use.

The reasons behind $S I$ '73's failure to impact on policy makers demonstrate quite clearly that better design, packaging, and other marketing efforts will not in their own right increase the power and utilization potential of the information. SI '73's graphic attributes received universal acclaim. Unfotunately, its aesthetic appeal did very little to enhance its usability, according even to those respondents who were not only familiar with it, but 
also favorably disposed. Dissemination was another negligible factor; respondents who received copies during the survey came to the same conclusion regarding its limited usefulness as those who were given free copies during OMB's initial dissemination or those who had bought their own.

Advances in social indicators. Clearly, then, the burden of increasing the usefulness of $S I$ ' 73 lies in the realm of content rather than marketing. That is, the information contained in the publication must somehow be made more powerful.

The field of social indicators has grown considerably around the world in the 40 years since President Hoover's Research Committee on Social Trends presented their 1933 report. Considerable advancements have been made in the development of social indicators as a concept, the measurement techniques involved, and in understanding the significance of indicators in national policy planning. Unfortunately, $S I$ ' 73 hardly reflects any of the progress made over the years in the ever-increasing efforts to use noneconomic measures to gauge social well-being. The authors, as well as others embarking on similar efforts in the future, would be well advised to familiarize themselves with the work going on in this country and elsewhere, particularly in the production of measures which are more inclusive, more comprehensive, more sophisticated, more important, and which go beyond the repertoire of simple objective, largely economic concerns - all of which would increase the power of social indicators. ${ }^{9}$ Undoubtedly, it will take many years before a national system of social accounting reaches maturity. Nevertheless, social indicator technology has grown out of its infancy stage and more progress has been made in that direction than was evident in $S I$ ' 73 .

National goals. So far we have focused our discussion on the importance of increasing the power of $S I$ ' 73 in view of the advances made in the social indicators field. However, the problem becomes more complex when we consider the larger implications inherent in the application of social indicators to policy matters.

While social statistics have already been widely accepted as instruments in policy making, the same is not true for social indicators. Most of the Federal officials in this study appeared to be aware of social indicators as a generic term. But under closer inspection, it became evident that they were only dimly aware of the full implications of social indicators and their potential use in policy making. Thus, substantial efforts might have to be made to institutionalize the importance of social indicators into governmental operations as powerful sources of information which are qualitatively different 
from 'mere' statistics, and, in terms of power, comparable to a non economic measure of social well-being along the lines of a GNP.

The promulgation of social indicators as valuable for planning will be an insufficient measure without a greater commitment from the Federal government to the value of social indicators in policy making and agenda setting. However, serious commitment by the government carries with it ramifications extending beyond mere publicity. The widespread use of social indicators would involve the acceptance of a system of national evaluation of progress. toward more clearly defined goals. The role of social indicators would then, of necessity, change from an occasional reference source for background information, to an important tool in policy formulation and program evaluation. The implications are considerable. For example, the U.S. government has long been criticized by many for being oriented to short term rather than long term directives. The acceptance of social indicators would necessarily carry with it a greater emphasis on social forecasting and long range planning throughout the various levels of government.

The progress toward deliberately selected national goals which social indicators are supposed to measure should influence the type of information collected and the form in which it is presented. $S I$ ' 73 , however, put the cart before the horse: its underlying philosophy seemed to be that if enough information could be assembled in one place it would have to be useful to someone. In fact, this catch-all style of information gathering appears to be prevalent in many government agencies where interest in social indicators seems great, at least on the surface. While, in Caplan's earlier study, most policy makers reported that an index of social well-being was a worthwhile idea and could name several measures relevant to their own operations, when asked what use they would make of such data, they gave such rambling and diverse responses that it was impossible to derive empirically based coding categories for purposes of quantification.

The tendency seems to be toward a widespread and often desultory collection of data conducted with the implicit hope that, somehow, from this pragmatic but goalless effort, some notions would evolve about what is the good life and how responsible government may help achieve it. A similar analysis of the Federal government's goalless pragmatism is echoed in the Presidential Commission on federal statistics (1974).

The basic difficulty lies in defining the goals of a program. In the words of an official responsible for planning and evaluation in a government agency, "When researchers say tell us what you want it appears that they are not aware that they have asked the hardest 
- perhaps the impossible - question of government". While it is hard to believe, the government is simply not good at defining what it wants to do in terms of needed social science research. It cannot meet the researcher's needs for clearly defined tasks. Any proposal to improve on the present state of affairs should recognize that the government in general, can only articulate the area in which it needs information, as exemplified ir the request, "Tell me something about mental health". But it does not seem to be able to get much below this, at least not on a broad front, to specify questions which might have interesting answers, and which might be answered by a single researcher or small group of researchers working part-time. The inability to specify the question to be answered, i.e., specify the goals, of a program, arises from the fact that the issue of what the government should be seeking to do is basically ideological, not factual.

The main point to be made is that the quantifiable and easily measurable should not be expected to provide the shape and direction of national goals. Goals should first be defined on other grounds, and only then should we devise the means for measuring them. It is in this sense that $S I$ ' 73 and other social indicator programs put the cart before the horse. That is, $S I$ ' 73 was a collection of indicators without an explicit organizing principle built around clearly defined national goals. Hence, $S I$ ' 73 found itself in the awkward position of being information which was not viewed by policy makers as particularly important, or necessary in their work. In our view, the nonimpact of SI '73 demonstrates that information without specified relatedness to a shared set of goal commitments lacks policy-shaping power because the data are not seen as relevant to the needs of policy makers.

Generation and interpretation of social indicators. The development of indicators implies more than the simple collection of data. The process involves decisions at all levels, on issues ranging from which data to collect to how to interpret it. The interpretation of what the indicators meant was an issue with many respondents who would have liked an accompanying interpretation of the trends, but who were also concerned that the source of interpretation should be neutral. Thus, assuming that national goals are clearly articulated and assuming the guiding function of implicit or explicit national goals in the design of social indicators, a question arises as to who should be responsible for the production of social indicators aimed at the upper policy echelons of the Federal government.

One thing demonstrated by the failure of $S I$ '73 was the lack of OMB's institutional capacity to produce a large scale social indicator volume with the relevant understanding and the expertise of HEW's Toward a Social Report. The answer might lie in the creation of new institutional arrangements in order to provide a continuous context for the generation and interpretation of social indicators by experts in an organizational setting designed just 
for that purpose. The arrangement, which would probably be quasi-political, would also necessitate bridges to a community of policy makers and other experts in the field. This would allow those responsible for producing social indicators to take into greater account the organizational and other factors affecting both the generation and application of social indicators. It is hoped that the end result would be as widespread a respect for the social indicators produced as is enjoyed by the Census Bureau for its work in demography.

Thus, at present, increasing the power of such data is largely a non-technical problem, in that it does not involve devising better measurements or better dissemination methods. The activities that must be involved include: (a) the deliberate setting of national goals; (b) the institutionalization of commitment to those goals throughout government; (c) agreement to the use of specific social indicators for the purpose of evaluating progress to achieving goal objectives; and (d) the establishment of bureaucratic arrangements with the capacity for legitimizing the importance of the informational value of the social indicators produced.

Given the complexities of the utilization process and the formidable technical problems in measuring the direct and indirect impacts of informational inputs into decision-making, it would be pretentious to argue that these recommendations represent anything more than a beginning in a area of accelerated interest where empirical research so far has been meager and scanty. Finally, we do not mean to imply that utilization will be guaranteed if all of these recommendations are met. But as a minimum, consideration must be given to this cluster of interrelated conditions if we are to develop the great potential of social indicators and to increase their systematic and creative application in the formulation of public policy and, in turn, the promotion of human welfare.

\section{University of Michigan}

\section{NOTES}

* The research reported here has been funded through Grant No. SOC $75-15800$ from
the National Science Foundation, whose support we gratefully acknowledge. The inter-
pretations and conclusions are those of the researchers and do not necessarily reflect the
views of the funding source. We wish to express our appreciation to Daniel Tunstall with
whom we had many long discussion prior to the research, as well as to the respondents
who participated in the study; also to Frances Updike Simonds and Sally Brenner for
their assistance in preparing the manuscript.
1 The research and development of Social Indicators, 1973 were directed by the Statis-
tical Policy Division of the Office of Management and Budget. The Report is available 
from the U.S. Government Printing Office, Washington, D.C. 20402 (Stock Number 0324-00256); $\$ 7.80$ ).

2 This work began with Recent Social Trends published by President Hoover's Research Committee on Social Trends (1933) and continued in various forms to the present OMB volume. It included the President's Commission on Naional Goals report, Goals for Americans (1960); the U.S. Department of Commerce's Historical Statistics of the United States (1960); the 1962 Supplement to Economic Indicators produced by the Bureau of the Budget; and HEW's Toward a Social Report in 1969. Probably no social science area has experienced as large a recent growth as the 'social indicator movement'. The desire of prominent social scientists to be useful has converged with favorable government funding policies to produce such a proliferation of literature in this area that even the most active workers have difficulty keeping abreast. In their 1973 publication, Social Indicators and Social Monitoring: An Annotated Bibliography, Wilcox et al. listed over 1000 U.S. articles alone - and then apologized for their incompleteness, explaining that articles on the topic were accumulating faster than could be reviewed and included.

${ }^{3}$ Respondents in the Caplan study had been asked to describe those social measures of particular interest to their work. Most of the following policy categories indicate measures highly regarded by respondents which were also included in $S I$ ' 73 .

(1) Health: The state of the nation's physical and, to a lesser degree, mental health; the accessibility and effectiveness of its health care delivery systems.

(2) Worker Satisfaction: Worker alienation; safety ana health issues; employment status among women and minority group members.

(3) Attitudes Toward Government and Other Institutions: Faith in major government institutions; trust in national leaders; and belief in the government's effectiveness in dealing with domestic problems; the declining influence of the family and school as institutions of social influence.

(4) Education: Level of literacy skills among the disadvantaged; opportunities for higher education.

(5) Housing: The quality of living conditions, including the adequacy of municipal services; quality and availability of housing for the economically disadvantaged and lower middle income groups; urban crowding.

(6) Environmental Quality: Level of environmental education and appreciation; avoidance of abuse; economic and health consequences of pollution; efforts to remove or lessen pollution.

(7) Military: Perception of the military by the public at large, and those in the military; recruitment.

(8) Demographic: Rural-urban migration patterns; land use distribution; trends in the patterning of society; population growth.

(9) Crime: Public safety; crime rate indices; recidivism; distributive justice; attitudes toward police and the judicial system in general.

(10) Recreation: Availability of discretionary time and income for leisure time activities; choice of recreational activities.

(11) Race Relations: Reduction of social conflict; trends in integration.

(12) Drugs: Trends in drug abuse and alcoholism.

(13) Transportation: Availability of efficient surface transportation; highway safety. - Immediately after the publication of $S I ' 73$, the Social Science Research Council (SSRC) convened a review symposium on the document and published the results in a volume edited by R. Van Dusen entitled, Social Indicators 1973: A Review Symposium. Those chapters by Zapf and Ramsey are highly critical of the indicators in $S I^{\prime} 73$ selected as measures for the policy areas.

s Although the respondents saw no special reason to discredit $S I{ }^{\prime} 73$ on the issue of objectivity, participants in the SSRC symposium argued that much of the data were open to serious scientific criticism. See in particular the chapter on statistical considerations by Fienberg and Goodman. They argue that (1) the data base for many indicators 
are methodologically weak and, (2) of ten times series data are illustrated in ways which are seriously misleading in the inferences they imply. Other participants (e.g., Zapf) stressed the biases in cultural values.

- Those interested in pursuing some of the definitional issues regarding social indicators may find value in: Social Indicators, ed. by R. Bauer (1966); the two volumes of the Annals of the American Academy of Political and Social Sciences, ed. by Gross (1967); the 800 page volume entitled Indicators of Social Change: Concepts and Measurement, published by the Russell Sage Foundation, ed. by Sheldon and Moore (1968); The Human Meaning of Social Change, ed. by Campbell and Converse (1972); Political Aspects of Social Indicators: Implications for Research by Henriot (1972); The HEW report, $A$ Report on Measurement and the Quality of Life by Walton J. Francis (1973); Social Indicators and Social Theory by Karl Fox (1974); Social Indicator Models, ed. by Land and Spilerman (1975); Subjective Measures of Well-Being by Campbell (1976); and Toward a Methodology for Social Indicators in Rural Development by Klonglan et al. (1976).

7 There is no intention here to demean the significance of social statistics. They are the form of social science used most frequently by upper-level federal executives in policyrelated matters. Such data account for about one-third of the empirically based social science knowledge used in such situations and are reported to be used across a wide range of governmental agencies with quite diverse interests, diverse target populations, and diverse missions (see Caplan, 1976b). However, with few exceptions, such as when a 'hot issue' arises and appropriate statistics are available, social statistics do not encompass a diversity of basic and applied activities, and therefore lack the potential for providing shape and direction for policy formulation which characterizes social indicators.

- This may seem to be a rather harsh judgment on $S I^{\prime} 73$. However, $S I^{\prime} 73$ does not match up the 1968 HEW Report, Toward a Social Report, in terms of its recognition of conceptual and practical difficulties of putting social indicators into use, nor does it provide 'better' information. $S I$ ' 73 simply provides more of it in better packaging.

9 Subjective indicators of social well-being, particularly as they relate to objective conditions and change programs are particularly prevalent in social indicator reports produced abroad. Persons planning to embark on future efforts to present social indicator data to public officials in the United States should examine, for example: The French Données sociales published in 1973; the West German Gesellschaftliche Daten 1973; the annual British Social Trends (particularly, Social Trends, No. 4, 1973); Sweden's Social Utveckling; and Norway's Sosialt Utsyn.

\section{BIBLIOG RAPHY}

Barton, E. and Rich, R.F.: 1976, 'Research utilization literature review', Unpublished report prepared for the NSF/RANN Task Force on Research Utilization (Institute for Social Research, Ann Arbor, Michigan).

Bauer, R. A. (ed. ) :: 1966, Social Indicators (MIT Press, Cambridge, Mass.).

Campbell, A.: 1976, 'Subjective measures of well-being', American Psychologist 31, pp. 117-124.

Campbell, A. and Converse, P. E.: (eds. ): 1972, The Human Meaning of Social Change (Russell Sage, New York).

Caplan, N. S.: 1976a, 'Social research and national policy: what gets used, by whom, for what purposes, and with what effects?', International Social Science Journal XXVII.

Caplan, N. S.: 1976b, 'The use of social statistics by federal executives with special attention to policy decisions in education', in Setting Statistical Priorities (The National Research Council, Washington, D. C.). 
Caplan, N. S., Morrison, A., and Stambaugh, R. J.: 1975, The Utilization of Social Science Knowledge in Policy Decisions at the National Level: A Report to Respondents (Institute for Social Research, (Ann Arbor, Mich.).)

Caplan, N.S. and Rich, R. F.: 1976, 'Open and closed knowledge inquiry systems: The process and consequences of bureaucratization of information policy at the national level', Paper presented at the meeting of the OECD Conference on Dissemination of economic and social development research results, Bogotá, Colombia, June 1976.

Federăl statistics: 1974, The President's Report 1, pp. 89-90.

Fox, K. A.: 1974, Social Indicators and Social Theory: Elements of an Operational System (Wiley, New York).

Gross, B.' (ed.).: 1967, 'Social goals and indicators for American society', Annals of the American Academy of Political and Social Science, Vols. 1 and 2.

Henriot, P. J.: 1972, Political Aspects of Social Indicators: Implications for Research (Russell Sage Foundation, New York).

Klonglan, G. E., Beal, G. M., Wilcox, L. D., Fear, F. A., and Wasson, K. W.: 1976, Toward a methodology for social indicators in rural development', Sociology Report 124, Department of Sociology and Anthropology, (Iowa State University, Ames, lowa).

Land, K.C. and Spilerman, S. (eds.): 1975, Social Indicator Models (Russell Sage, New York).

President's Commission on National Goals: 1960, Goals for Americans (Prentice Hall, Englewood Cliffs, New Jersey).

President's Research Committee in Social Trends: 1933, Recent Social Trends in the United States (McGraw-Hill, New York).

Rich, R.F. and Barton, E.: 1976, Research utilization: Attitudes, expectations, and action of NSF/RANN program managers and upper management', Unpublished report prepared for the NSF/RANN Task Force on Research Utilization (Institute for Social Research, Ann Arbor, Michigan).

Sheldon, E. B and Moore, W. E (eds.): 1968, Indicators of Social Change: Concepts and Measurements (Russell Sage, New York).

' 1962 Supplement to economic indicators: historical and descriptive background', Prepared for the Joint Economic Committee by the Committee Staff and the Office of Statistical Standards, Bureau of the Budget, 87th Congress, 2nd Session (U.S. Goversment Printing Office, Washington, D. C.).

U.S. Department of Commerce: 1960, Historical Statistics of the United States Colonial Times to 1957 (U.S. Government Printing Office, Washington, D. C.).

U.S. Department of Health, Education, and Welfare: 1969, Toward a Social Report, (U.S. Goversment Printing Office, Washington, D. C.).

U.S. Department of Health, Education, and Welfare: 1973, A Report on Measurement and the Quality of Life (Washington, D. C.).

U.S. Office of Management and Budget: 1973, Social Indicators, 1973 (U.S. Government Printing Office, Washington, D. C.).

Van Dusen, R. (ed.): 1974, 'Social Indicators 1973: A Review Symposium (Social Science Research Council, Washington, D. C.).

Wilcox, L. D., Brooks, R. M., Beal, G. M., and Klonglan, G. E.: 1972, Social Indicators and Societal Monitoring: An Annotated Bibliography (Jossey-Bass, San Francisco, Calif.). 